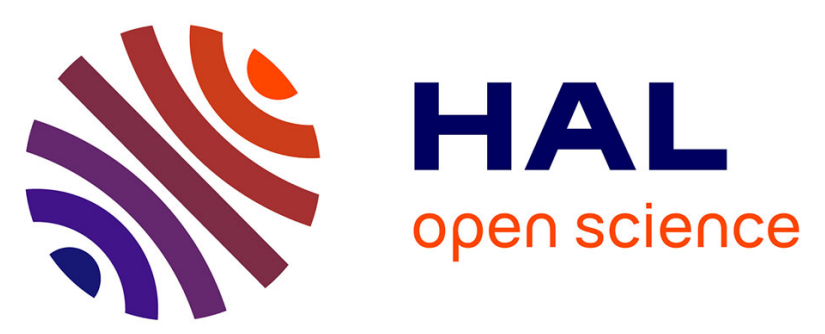

\title{
From 1D to 2D arrangements of graphite flakes in an aluminium matrix composite: impact on thermal properties
}

Zhengyan Shen, Gang Ji, Jean-François Silvain

\section{To cite this version:}

Zhengyan Shen, Gang Ji, Jean-François Silvain. From 1D to 2D arrangements of graphite flakes in an aluminium matrix composite: impact on thermal properties. Scripta Materialia, 2020, 183, pp.86-90. 10.1016/j.scriptamat.2020.03.022 . hal-02524052

HAL Id: hal-02524052

https://hal.univ-lille.fr/hal-02524052

Submitted on 24 Sep 2020

HAL is a multi-disciplinary open access archive for the deposit and dissemination of scientific research documents, whether they are published or not. The documents may come from teaching and research institutions in France or abroad, or from public or private research centers.
L'archive ouverte pluridisciplinaire HAL, est destinée au dépôt et à la diffusion de documents scientifiques de niveau recherche, publiés ou non, émanant des établissements d'enseignement et de recherche français ou étrangers, des laboratoires publics ou privés. 


\title{
From 1D to $2 \mathrm{D}$ arrangements of graphite flakes in an aluminium matrix composite : impact on thermal properties
}

\author{
Zhengyan Shen ${ }^{1,2}$, Gang $\mathrm{Ji}^{*}$, Jean-François Silvan ${ }^{1,3}$ \\ ${ }^{1}$ CNRS, Univ. Bordeaux, Bordeaux INP, ICMCB, UMR 5026, 33600 Pessac, France \\ 2 UMR 8207 - UMET - Unité Matériaux et Transformations, University of Lille, CNRS, INRA, ENSCL, F-59000 Lille, France \\ ${ }^{3}$ Department of Electrical and Computer Engineering, University of Nebraska-Lincoln, Lincoln, NE, 68588, United States
}

Abstract : The 2D arrangement of highly-anisotropic graphite flake $\left(\mathrm{G}_{\mathrm{f}}\right)$ in the Al matrix composite was achieved by combining the step-by-step powder filling method and flake powder metallurgy using the specifically-designed punch. Compared with the conventional 1D arrangement, its advantages are to improve thermal conductivity as well as to reduce coefficient of thermal expansion being compatible with that of the substrate material. This technical advance can open up a door towards thermal management applications of the low-cost $\mathrm{G}_{\mathrm{f}} / \mathrm{Al}$ composites.

Keywords : Aluminium/graphite ; Metal matrix composites; Thermal properties ; Architecture of reinforcements ; Sintering. * Corresponding author : e-mail address : gang.ji@univ-lille.fr

Over the last decades, the significant increase of power densities in microelectronic (nano)devices has attracted material scientists to develop novel materials for thermal management applications [1,2], with the aim to improve efficiency of heat dissipation and decreasing local thermal stresses occurred in service. Carbon-based (e.g. graphite, diamond and carbon fibre) materials, due to their excellent thermal properties, have been tentatively integrated into a metal matrix (e.g. Al, $\mathrm{Cu}$ ) to increase its thermal conductivity (TC) as well as to tailor its coefficient of thermal expansion (CTE) [3], [4], [5], [6], [7]. Among them, graphite flake $\left(\mathrm{G}_{\mathrm{f}}\right) /$ metal composite has drawn more and more attentions, because it is low cost and has good machinability compared with diamond/metal composite [4,[7], [8], [9], [10].

Indeed, the Gf exhibits a high in-plane TC of around $1000 \mathrm{~W} / \mathrm{mK}$ [11], while the out-of-plane TC is only in the range 5-10 W/mK [12]. Due to this anisotropic characteristic, perfect alignment of $\mathrm{G}_{\mathrm{f}}$ in the Al matrix becomes necessary to acquire a high overall TC of the composite along the direction being parallel to $\mathrm{G}_{\mathrm{f}}$ plane. This is easily achievable by using liquid phase routes, such as gas infiltration [13] and squeeze casting [7], due to the fact that $\mathrm{G}_{\mathrm{f}}$ tends to array on the top of each other. It was also reported that the alignment of $\mathrm{G}_{\mathrm{f}}$ is feasible via a step-by-step powder loading method (i.e. powder metallurgy) [14]. Further, Nabil et al. reported that highly aligned $\mathrm{G}_{\mathrm{f}}$ in the $\mathrm{Al}$ matrix has been realized using a flake Al powder by hot pressing [10], so-called flake powder metallurgy being initially developed to produce the CNT/Al composite [15]. This is mainly because the apparent density of flake powder is smaller than that of spherical one, increasing spaces for orientation along the plane direction during cold pressing [16]. As a result, TC of the aligned $\mathrm{G}_{\mathrm{f}} / \mathrm{Al}$ composite has been improved, for example, the in-plane TC of higher than $420 \mathrm{~W} / \mathrm{mK}$ can be achieved with the $\mathrm{G}_{\mathrm{f}}$ content higher than $40 \%$, while the out-of-plane TC remains lower than $70 \mathrm{~W} / \mathrm{mK}$ $[8,10,13]$.

Regarding thermal matching, the $\mathrm{G}_{\mathrm{f}}$ also has high anisotropy in CTE (-1 $\times 10^{-6} / \mathrm{K}$ in-plane, $28 \times 10^{-6} / \mathrm{K}$ out-of-plane [17]). However, it was reported in the aligned $\mathrm{G}_{\mathrm{f}} / \mathrm{Al}$ composite that the overall CTE along the base plane of graphite merely decreases from $25 \times 10^{-6} / \mathrm{K}$ to $22 \times 10^{-6} / \mathrm{K}$ when the volume fraction of $\mathrm{G}_{\mathrm{f}}$ increases up to $50 \%$ [9]. Comparatively, the CTE along the direction perpendicular to the plane decreases drastically even reaching negative values $[18,19]$.

Therefore, such above-mentioned high anisotropies of the $\mathrm{G}_{\mathrm{f}}$ gave rise to major obstacles in fabrication once both TC and CTE should be taken into account for potential applications. Taking an example of a flat heat sink material pressed against a silicon wafer as shown in Fig. 1a, the high in-plane TC (along $Z$ direction) can be expected by the $G_{f}$ alignment for effectively dissipating heat generated from the Si wafer. However, this 1D arrangement configuration cannot allow to tailor the out-of-plane CTE (in $X-Y$ plane) being incompatible with that of the Si wafer (around $4 \times 10^{-6} / K$ ) [20]. 
(a)

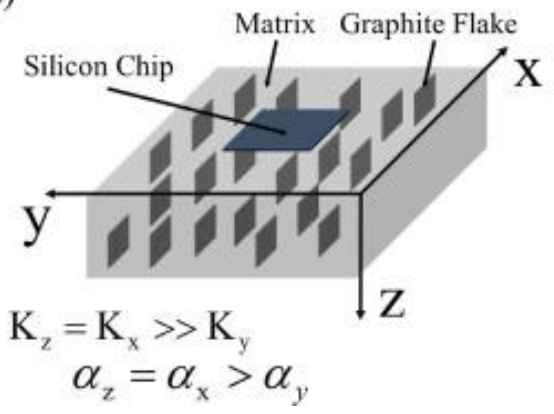

(b)

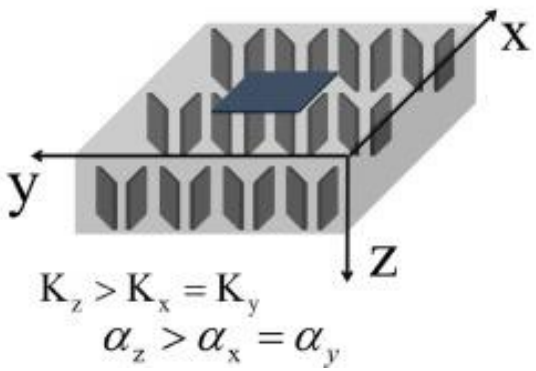

Fig. 1. : Schematic illustrations of the $1 D(a)$ and $2 D(b)$ arrangements of $G_{f}$ in a metal matrix with respective to the silicon ship and their configurations of thermal properties (K: TC; $\alpha$ : CTE).
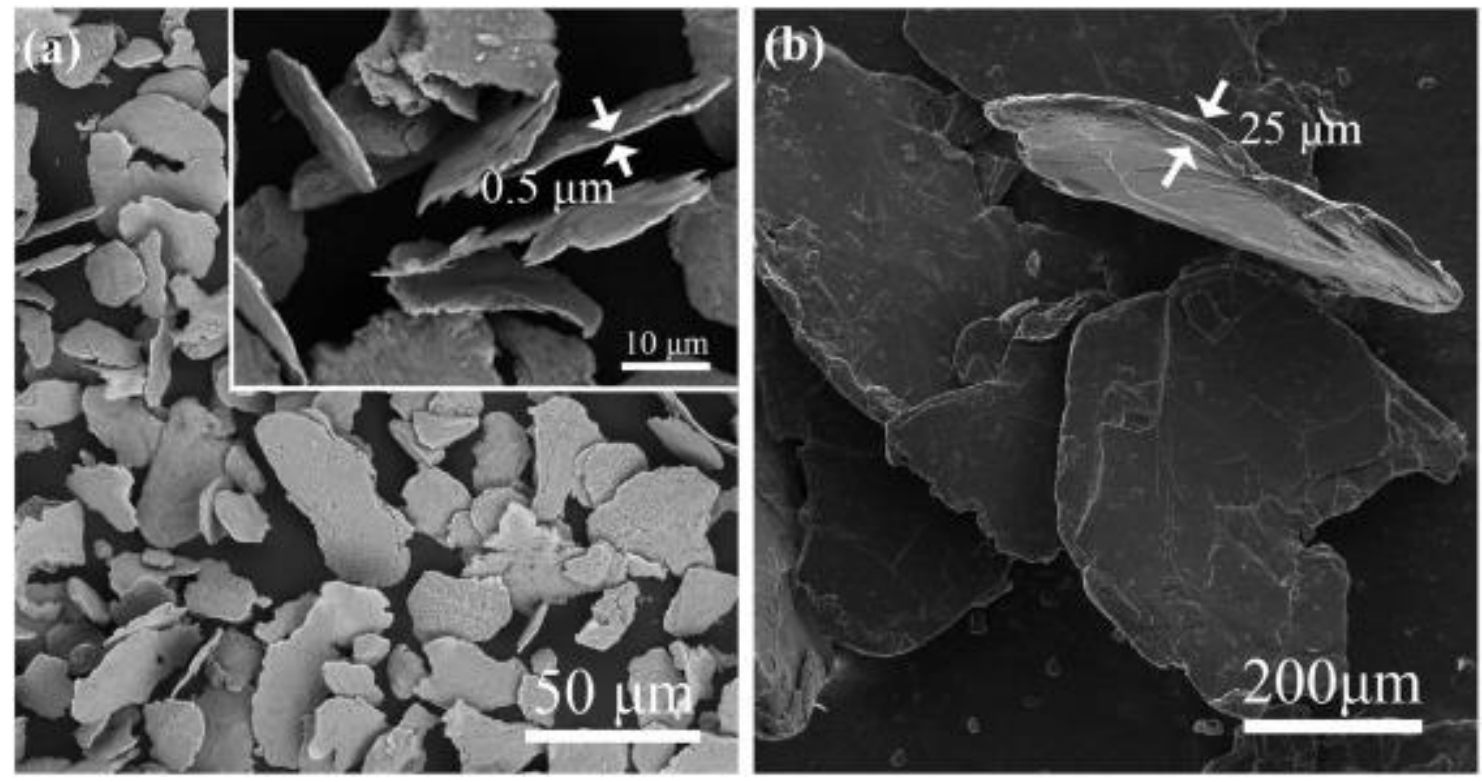

Fig. 2. SEM images showing the morphologies of the starting materials: (a) as-milled flake Al powder and (b) as-received $\mathrm{G}_{\mathrm{f}}$.

The objective of this work aims at addressing the technical challenge for developing a novel method to achieve the 2D arrangement by flake powder metallurgy using a specifically designed punch associated with the step-by-step powder filling process. In this way as shown in Fig. 1b, the improved TC benefited from the 1D arrangement can be conserved. In addition, the incompatible CTE in the X-Y plane can be tailored to be approximate to that of the Si wafer.

Flake Al powder with the average thickness smaller than $1 \mu \mathrm{m}$ (Fig. 2a) was produced from gas-atomized spherical Al powder (ULTD0065, Hermillon powders, France) via ball milling in isopropyl alcohol at $200 \mathrm{rpm}$ for $30 \mathrm{~min}$. G $\mathrm{f}$ was purchased from YanxinGraphite Co., Ltd. As shown in Fig. 2b, it has the average diameter and thickness of 500 and $25 \mu \mathrm{m}$, respectively. The $\mathrm{G}_{\mathrm{f}}$ was firstly ultrasonically washed in ethanol for $10 \mathrm{~min}$, filtered by filter paper and dried in a drying chamber. Subsequently, the $\mathrm{G}_{\mathrm{f}}$ was homogenously mixed with the flake Al powder using a resonant acoustic mixer for $10 \mathrm{~s}$ with an acceleration of $70 \mathrm{~g}$ (LabRAM, Butte, Montana, USA), in which the volume fraction of $\mathrm{G}_{\mathrm{f}}$ was set to $40 \%$.

Quantity of the $\mathrm{G}_{\mathrm{f}} / \mathrm{Al}$ mixture for one specimen was calculated according to both the final size $(20 \times 20 \times 8 \mathrm{~mm})$ of sample and theoretical density obtained by rule of mixture. The fabrication process to introduce the $2 \mathrm{D}$ arrangement of $\mathrm{G}_{\mathrm{f}}$ is illustrated in Fig. 3. First, the powder mixture with proper quantity was loaded in a graphite mould with rectangle cavity $(12 \times 20 \mathrm{~mm}$, Fig. 3a) and cold pressed at $2 \mathrm{MPa}$ using a punch with groove (the angle of $150^{\circ}$ and width of $4 \mathrm{~mm}$ ) to form a layer of powder with the thickness close to $0.5 \mathrm{~mm}$. The morphology of powder layer after one step cold pressing is shown in Fig. $3 \mathrm{~b}$. This step was repeated until the height of precursor (Fig. 3c) close to $20 \mathrm{~mm}$. Second, the precursor was completely removed out of the mould and was turned $90^{\circ}$. It was then loaded in another mould with square cavity $(20 \times 20 \mathrm{~mm}$, Fig. 3d) for hot sintering in order to obtain the final product (Fig. 3e). For comparison, the $1 \mathrm{D}$ alignment of $\mathrm{G}_{\mathrm{f}}$ was acquired using a flat punch via the same process of powder filling. 
All bulk specimens were fabricated via hot pressing under vacuum $\left(1.5 \times 10^{-1} \mathrm{mbar}\right)$ at the optimized condition $\left(620^{\circ} \mathrm{C}, 60 \mathrm{MPa}\right.$ for $30 \mathrm{~min}$ ). Hot pressing direction is noted as $y$ in Fig. 3, while the $x$ and $z$ directions are the same as given in Fig. 1 for both 1D and $2 \mathrm{D}$ arrangements. The as-sintered samples were sectioned along the xy planes and mounted in thermosetting resin for examination using scanning electron microscopy (SEM) (Tescan, VEGA ${ }^{\circledR}$ ). Image analysis of SEM micrographs was done using Image J software to measure the angle $(\theta)$ of each flake with respect to the $x z$ plane and to determine an angle distribution. $A$ FEI Tecnai G2 microscope, operated at $200 \mathrm{kV}$, was used for transmission electron microscopy (TEM). TEM samples were prepared by mechanical polishing and final ion milling.

TC of the composite was calculated using thermal diffusivity, density, and heat capacity where thermal diffusivity was obtained by laser flash technique (NETZSCH LFA 45 , Miroflash) at $70^{\circ} \mathrm{C}$. Thermo-physical properties of the raw materials was given in Ref. [10]. The sample dimensions for thermal diffusivity measurement were $\Phi 6 \times 4 \mathrm{~mm}$. CTE were measured by dilatometry (NETZSCH DIL $402 \mathrm{PC}$ ) in the temperature range 50 to $100^{\circ} \mathrm{C}$ with the heating rate of $2^{\circ} \mathrm{C} / \mathrm{min}$. The samples used were cut into a cubic shape $(5 \times 5 \times 5 \mathrm{~mm})$.

(a)

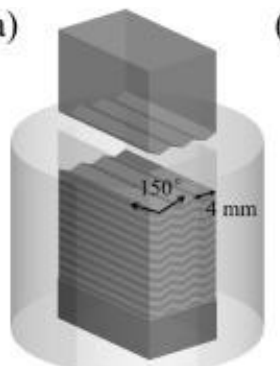

Cold pressing (b)

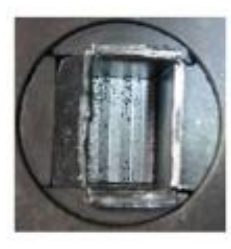

(c)

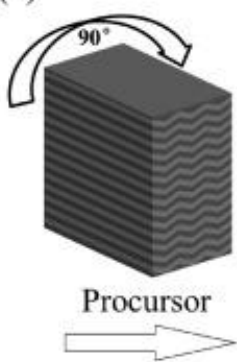

(d)

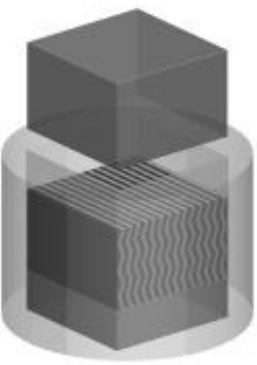

Hot pressing (e)

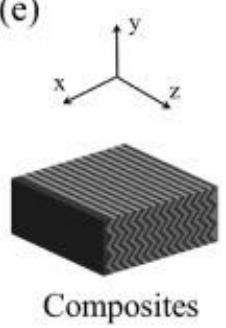

Composites

Fig. 3. Schematic illustrations of the whole fabrication process to acquire a $\mathrm{G}_{f} / \mathrm{Al}$ composite with the $2 \mathrm{D}$ arrangement: (a) cold pressing using the specifically-designed punch, (b) photograph of the powder layer morphology after cold pressing, (c) $\mathrm{G}_{\mathrm{f}} / \mathrm{Al}_{\mathrm{l}}$ procursor, (d) vacuum hot pressing, and (e) final product.
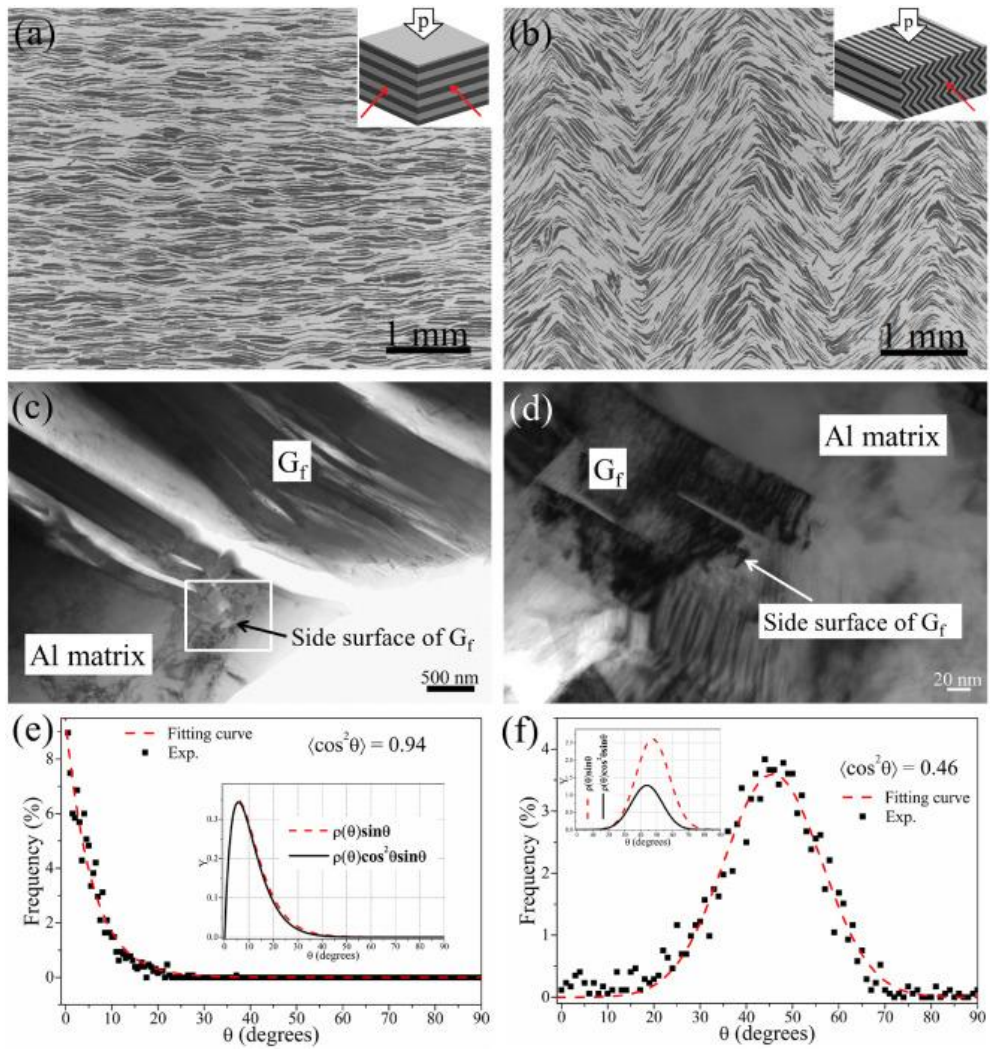

Fig. 4. SEM images showing (a) the $1 \mathrm{D}$ and (b) $2 \mathrm{D}$ arrangements of $\mathrm{G}_{\mathrm{f}}$ in the composites, (c) low-magnification and (d) highmagnification (zoom-in of the box area in (c)) TEM images highlighting the typical side surface $\mathrm{G}_{f} /$ Al interface, corresponding statistical distribution graphs of the angle $\theta$ between the direction parallel to the $\mathrm{G}$ plane and the in-plane direction of the composite sample in (e) the 1D and (f) 2D cases. Determination of $\left\langle\cos ^{2} \theta\right\rangle$ based on the image analysis of frequency versus $\theta$ from the corresponding cross-sectional images. Plots were fitted by the "nonlinear curve fit" process by Origin software. 
Table 1

Thermal properties of the $\mathrm{G}_{\mathrm{f}} / \mathrm{Al}$ composites with $1 \mathrm{D}$ and $2 \mathrm{D}$ arrangements.

\begin{tabular}{|c|c|c|c|c|c|}
\hline Arrangements & $1 \mathrm{D}$ & & & $2 \mathrm{D}$ & \\
\hline $\mathrm{TC}(\mathrm{W} / \mathrm{mK})$ & $z x: 431 \pm 6$ & $y: 41 \pm 1$ & $\mathrm{x}: 81 \pm 1$ & y: $191 \pm 1$ & $z: 437 \pm 3$ \\
\hline CTE $\left(10^{-6} / \mathrm{K}\right)$ & $\mathrm{zx}: 23.4 ; 45^{\circ}: 3.0$ & $y:-19.3$ & $x: 5.3$ & $y: 6.7$ & $\mathrm{z}: 22.0$ \\
\hline
\end{tabular}

Thermal diffusivity and CTE were measured along the directions parallel and perpendicular to the $y$ (i.e. pressing) axis in the 1D case (Fig. 1a), while along the $x, y$ and $z$ axes in the 2D case (Fig. 1b). CTE along the direction having the angle of $45^{\circ}$ with respect to the $\mathrm{G}_{\mathrm{f}}$ plane in the $1 \mathrm{D}$ case was measured as well. Relative density was measured using the Archimedes' method.

Figs. $4 \mathrm{a}$ and $\mathrm{b}$ show the overview of the typical composites with the $1 \mathrm{D}$ and $2 \mathrm{D}$ arrangements, respectively. It should be noticed that the micrographs cover an area of $5.7 \times 4.3 \mathrm{~mm}$, which can stand for two third of the sample thickness. Corresponding to the measured relative densities of almost $100 \%$, no porosity was observed in both processed samples. High orientation of $\mathrm{G}_{\mathrm{f}}$ perpendicular to the pressing direction can be clearly observed from the cross-sectional view as shown in Fig 4 a, which is consistent with the previous report [10]. Use of the newly-designed punch with the zigzag shape results in the wave-like distribution of $\mathrm{G}_{\mathrm{f}}$ as shown in Fig. 4b. TEM bright-field images (Figs. 4c and d) show one example of a 'clean' and tightly-bonded side surface $\mathrm{G}_{f} / \mathrm{Al}$ interface (perpendicular to the direction for thermal diffusivity measurements) where no plate-like $\mathrm{Al}_{4} \mathrm{C}_{3}$ due to interfacial reaction and no interfacial porosity are observed. As was revealed in $[6,21]$, this so-called diffusion-bonded interface should be the favourable interface structure for minimizing interfacial thermal resistance and, in turn, for overall TC enhancement.

The orientation degrees of $\mathrm{G}_{\mathrm{f}}$ in the $1 \mathrm{D}$ and $2 \mathrm{D}$ cases were evaluated by the parameter of $\left\langle\cos ^{2} \vartheta\right\rangle$, given in reference [22].

$$
\left\langle\cos ^{2} \theta\right\rangle=\frac{\int \rho(\theta) \cos ^{2} \theta \sin \theta \mathrm{d} \theta}{\int \rho(\theta) \sin \theta \mathrm{d} \theta}
$$

Herein, $\vartheta$ is the angle of each flake with respect to the xz plane ranging from $0^{\circ}$ to $90^{\circ} \rho(\theta)$ represents the statistical distribution of angles of the reinforcements in the Al matrix. Specifically, this angle distribution can be expressed as plots of frequency (fraction of $G_{f}$ for a given $\theta$ ) versus $\theta$ as shown in Fig. 4 e and f. For the $1 D$ arrangement, it was given by $[23,24]$,

$$
\rho(\theta)=\mathrm{A}_{1} \mathrm{e}^{\left(-\theta / \mathrm{t}_{1}\right)}+\mathrm{y}_{0}
$$

and for the 2D arrangement, Gaussian function is used to do fitting,

$$
\rho(\theta)=\mathrm{Ae}^{\left(-\frac{\left(\theta-\mathrm{C}^{2}\right.}{\mathrm{w}^{2}}\right)}+\mathrm{y}_{1}
$$

where $A 1, t_{1}, y_{0}, A, C, W$, and $y_{1}$ refer to the fitting parameters. The $\left\langle\cos ^{2} \theta\right\rangle$ values can be determined by substitution $\rho(\theta)$ with the obtained fitting parameters into Eq. (1), and doing integration by Origin software, as shown in the insets of Figs. 4e and f.

Theoretically, the $\left\langle\cos ^{2} \theta\right\rangle$ describes the orientation of $\mathrm{G}_{\mathrm{f}}$ along a certain direction depending on the definition of angle $\theta$. With the fully well-orientation of $\mathrm{G}_{\mathrm{f}}$ along the in-plane direction of the composite specimen, $\left\langle\cos ^{2} \theta\right\rangle$ is equal to 1 , and for the completely random distribution of $\mathrm{G}_{f},\left\langle\cos ^{2} \theta\right\rangle$ is equal to $1 / 3$ [23], [24], [25]. In this work, the value of $\left\langle\cos ^{2} \theta\right\rangle$ obtained from distribution graph of the sample with the $1 \mathrm{D}$ arrangement is 0.94 . However, the value of the $2 \mathrm{D}$ arranged sample is 0.46 , which gives an approximately isotropy distribution of $\mathrm{G}_{\mathrm{f}}$. This means that the arrangement of $\mathrm{G}_{\mathrm{f}}$ can be tailored by the combination of flake powder metallurgy using the specifically-designed punch and the step-by-step powder filling method.

The measured TC and CTE values of the composites were given in Table 1 in order to validate our method. High anisotropies of the TC and CTE values along the in-plane and out-of-plane directions are clear in the sample with the conventional 1D arrangement. In particular, the CTE along the in-plane direction remains almost unchanged compared to that of the pure Al $\left(26 \times 10^{-6} / \mathrm{K}\right)$, while the CTE becomes negative along the out-of-plane direction. The CTE measured along the direction having $45^{\circ}$ with respect to the basic plane is $3.0 \times 10^{-6} / \mathrm{K}$, being close to half of the sum of CTEs along the in-plane and out of plane directions. Applying the 2D arrangement, as a new architecture, maintains the TC $(437 \mathrm{~W} / \mathrm{mK})$ along the $\mathrm{z}$ direction (perpendicular to the $2 \mathrm{D}$ arrangement plane) as high as that ( $431 \mathrm{~W} / \mathrm{mK})$ of the $1 \mathrm{D}$ arrangement. Further, the anisotropy degree of CTE in the 2D arrangement plane becomes small where both CTEs are as low as around $5-6 \times 10^{-6} / \mathrm{K}$, considered as compatible with that of silicon chips in the microelectronic industry. 
In conclusion, we developed a new processing process using the step-by-step powder filling method together with flake powder metallurgy in order to produce the $\mathrm{G}_{f}(40$ vol.\%)/Al composite material with the $2 \mathrm{D}$ arrangement. Compared with the conventional 1D arrangement, this specially-designed architecture enables to acquire not only the high TC but also the low CTE being compatible with that of the substrate material. This thus makes a step forward to use this low-cost material for thermal management applications.

\section{Declaration of Competing Interests}

The authors declare that they have no known competing financial interests or personal relationships that could have appeared to influence the work reported in this paper.

\section{Acknowledgements}

Financial supports of Zhengyan Shen's Ph.D. thesis were from the China scholarship council (No. 201606890034), University of Bordeaux, and Centre National de la Recherche Scientifique (CNRS). The TEM facility in Lille (France) is supported by the Conseil Régional du Nord-Pas de Calais, and the European Regional Development Fund (ERDF).

\section{References}

1. D.D.L. Chung. Appl. Therm. Eng, 21 (2001), pp. 1593-1605.

2. C. Zweben. JOM, 50 (1998), pp. 47-51.

3. Z. Tan, Z. Li, G. Fan, X. Kai, G. Ji, L. Zhang, D. Zhang. Compos. Part B: Eng., 47 (2013), pp. 173-180.

4. R. Prieto, J.M. Molina, J. Narciso, E. Louis. Scr. Mater, 59 (2008), pp. 11-14.

5. H. Kurita, E. Feuillet, T. Guillemet, J.-.M. Heintz, A. Kawasaki, J.-.F. Silvain. Acta Metallur. Sin. (English Letters), 27 (2014), pp. 714-722.

6. C. Zhou, G. Ji, Z. Chen, M. Wang, A. Addad, D. Schryvers, H. Wang. Mater. Des., 63 (2014), pp. 719-728.

7. W. Li, Y. Liu, G. Wu. Carbon, 95 (2015), pp. 545-551.

8. J.K. Chen, I.S. Huang. Compos. Part B: Eng., 44 (2013), pp. 698-703.

9. H. Kurita, T. Miyazaki, A. Kawasaki, Y. Lu, J.-.F. Silvain. Compos. Part A: Appl. Sci. Manuf., 73 (2015), pp. 125-131.

10. N. Chamroune, D. Mereib, F. Delange, N. Caillault, Y. Lu, J.-.L. Grosseau-Poussard, J.-.F. Silvain. J. Mater. Sci., 53 (2018), pp. 8180-8192.

11. M. Murakami, N. Nishiki, K. Nakamura, J. Ehara, H. Okada, T. Kouzaki, K. Watanabe, T. Hoshi, S. Yoshimura. Carbon, 30 (1992), pp. 255-262.

12. Q. Fu, J. Yang, Y. Chen, D. Li, D. Xu. Appl. Phys. Lett., 106 (2015), Article 031905.

13. C. Xue, H. Bai, P.F. Tao, J.W. Wang, N. Jiang, S.L. Wang. Mater. Des., 108 (2016), pp. 250-258

14. C. Zhang, X. He, Q. Liu, S. Ren, X. Qu. J. Compos. Mater, 49 (2014), pp. 3323-3330.

15. L. Jiang, Z. Li, G. Fan, L. Cao, D. Zhang. Carbon, 50 (2012), pp. 1993-1998.

16. X.Z. Kai, Z.Q. Li, G.L. Fan, Q. Guo, D.B. Xiong, W.L. Zhang, Y.S. Su, W.J. Lu, W.J. Moon, D. Zhang. Mater. Sci. Eng. A, 587 (2013), pp. 46-53.

17. N. Chamroune, F. Delange, N. Caillault, F. Morvan, Y. Lu, A. Kawasaki, J.-.F. Silvain. Met. Mater. Int., 26 (2019), pp. $155-167$.

18. V. Oddone, R.C. Wimpory, S. Reich. J. Mater. Sci., 54 (2019), pp. 1267-1274.

19. V. Oddone, B. Boerner, S. Reich. Sci. Technol. Adv. Mater, 18 (2017), pp. 180-186.

20. K. Kuniya, H. Arakawa, T. Kanai, T. Yasuda. IEEE Trans. Comp. Hybrids Manuf. Technol., 6 (1983), pp. 467-472.

21. Z. Tan, G. Ji, A. Addad, Z. Li, J.-.F. Silvain, D. Zhang. Compos. Part A: Appl. Sci. Manuf., 91 (2016), pp. 9-19.

22. C.-.W. Nan, R. Birringer, D.R. Clarke, H. Gleiter. J. Appl. Phys, 81 (1997), pp. 6692-6699.

23. Y. Sohn, T. Han, J.H. Han. Carbon, 149 (2019), pp. 152-164.

24. K. Chu, X.-h. Wang, F. Wang, Y.-b. Li, D.-j. Huang, H. Liu, W.-I. Ma, F.-x. Liu, H. Zhang. Carbon, 127 (2018), pp. $102-112$.

25. C. Zhou, W. Huang, Z. Chen, G. Ji, M.L. Wang, D. Chen, H.W. Wang. Compos. Part B: Eng., 70 (2015), pp. 256-262. 